\title{
Recombinant Human Thyrotropin-Stimulated Radioiodine Therapy in Patients with Multinodular Goiters: A Meta-Analysis of Randomized Controlled Trials
}

Authors

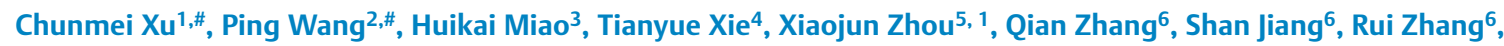
Lin Liao 5,1 , Jianjun Dong6

Affiliations

1 Department of Endocrinology and Metabology, Shandong Provincial Qianfoshan Hospital, Shandong University, Jinan, Shandong, China

2 Department of Endocrinology, Dezhou Municiple Hospital, Dezhou, Shandong, China

3 Department of Thoracic Oncology, Sun Yat-sen University Cancer Center, Guangzhou, China

4 Department of Endocrinology, Shandong University of Traditional Chinese Medicine, Jinan, Shandong, China

5 Department of Endocrinology and Metabology, The First Affiliated Hospital of Shandong First Medical University, Jinan, Shandong, China

6 Department of Endocrinology, Qilu Hospital, Shandong University, Jinan, Shandong, China

Key words multinodular goiters, recombinant human thyrotropin, radioiodine therapy, meta-analysis

received 05.05 .2020

accepted after revision $\quad 07.08 .2020$

published online $\quad 23.09 .2020$

Bibliography

Horm Metab Res 2020; 52: 841-849

DOI 10.1055/a-1240-5058

ISSN 0018-5043

(C) 2020. Thieme. All rights reserved.

Georg Thieme Verlag KG, Rüdigerstraße 14,

70469 Stuttgart, Germany

Correspondence

Lin Liao Ph.D.

Department of Endocrinology and Metabology

The First Affiliated Hospital of Shandong First Medical

University

No.16766, Jingshi Road,

Lixia District Jinan

Shandong Province

250014

P. R. China

Tel.: + 8615168888260

liaolin@sdu.edu.cn
Jianjun Dong Ph.D.

Department of Endocrinology

Qilu Hospital, Cheeloo College of Medicine, Shandong

University

No.44, Wenhuaxi Road Lixia District

Jinan Shandong Province

250012

P. R. China

Tel.: + 8613791122910

cwc_II@sdu.edu.cn

\section{ABSTRACT}

A potential reduction of goiter volume (GV) of recombinant human thyrotropin (rhTSH) on multinodular goiters (MNG) was previously reported but controversial. Hence we conducted a meta-analysis to estimate the effect of rhTSH-stimulated radioiodine therapy in patients with MNG. PubMed, Cochrane, CNKI, VIP, and Wanfang databases were searched. Mean difference (MD) and odds ratios with $95 \%$ confidence intervals (95\% $\mathrm{Cl}$ ) were derived by using an inverse variance random-effects model and fixed-effects model, respectively. Six studies $(n=237)$ were involved in the analysis. For 12 months follow up, high dose ( $>0.1 \mathrm{mg}$ ) of rhTSH significantly reduced GV $(\mathrm{MD}=17.61 ; 95 \% \mathrm{Cl}=12.17$ to $23.04 ; \mathrm{p}<0.00001)$ compared with placebo. No effective pooled results of low dose of rhTSH $(<0.1 \mathrm{mg}$ ) were applicable for only one study included. For 6 months follow up, the source of heterogeneity was determined by subgroup and sensitivity analysis. High dose group showed vast improvement in GV reduction (MD $=16.62 ; 95 \%$ $\mathrm{Cl}=1.34$ to $31.90 ; \mathrm{p}=0.03$ ). The reduction of low dose group compared with placebo was inferior to high dose group. No available data were obtained to assess the influence of rhTSH after 36 months follow up for the only included study. Hypothyroidism incidence was higher for rhTSH group. No publication bias was seen. High dose of rhTSH treatment-stimulated radioactive ${ }^{131}$ I therapy after 6 months and 12 months follow up had a better effect in reducing $G V$, but with higher incidence of hypothyroidism. Owing to the limited methodological quality, more clinical researches are warranted in the future.

\# Co-first authors. 


$\begin{array}{ll}\text { ABBREVIATIONS } \\ \text { RhTSH } & \text { Recombinant human thyrotropin } \\ \text { CI } & \text { Confidence interval } \\ \text { MD } & \text { Mean difference } \\ \text { MNG } & \text { Multinodular goiter } \\ \text { LT4 } & \text { Levothyroxine } \\ \text { GV } & \text { Goiter volume } \\ \text { RAIU } & \text { 131I uptake } \\ \text { RCTS } & \text { Randomized controlled trials } \\ \text { WMD } & \text { Weighted mean differences } \\ \text { SMD } & \text { Standardized mean difference } \\ \text { OR } & \text { Odds ratio }\end{array}$

\section{Introduction}

Multinodular goiter (MNG) is a very common thyroid disorder associated with diverse goitrogenic factors. Observation may be appropriate in euthyroid and asymptomatic patients. But there are still lots of patients who require treatment due to compression symptoms of local structures and thyroid hyperfunction [1]. Therapeutic options include levothyroxine (LT4) [2], surgery [3], and radioiodine. LT4 therapy is discouraged for low efficacy $[4,5]$ when compared with surgery or radioiodine. Thyroidectomy is an effective option but is often refused by the patients for the potential risk of surgical complications [6].

Studies have shown optimism for the potential of radioactive ${ }^{131}$ I therapy [7], which can reduce the mean goiter volume (GV) by approximately $40 \%$ within 1 year [8], as a therapeutic option for MNG. However, in some cases, ${ }^{131}$ I therapy is less attractive because some MNG patients have a low ${ }^{131}$ I uptake (RAIU) resulting in a relatively low ${ }^{131}$ I activity, which is needed for satisfactory goiter shrinkage.

Recombinant human TSH (rhTSH) can increase the thyroid RAIU by more than 2-fold in MNG patients and normal subjects [9, 10]. Thus, it has been evaluated as an adjuvant to ${ }^{131}$ I in the treatment of MNG. Studies [11,12] demonstrated that a single low dose of rhTSH increased considerably the RAIU in patients with MNG. But whether rhTSH combined with ${ }^{131}$ I therapy showed a GV reduction advantage and what is the suitable dose and length of therapy are disputed. Albino et al. showed that GV reductions were not statistically different in patients treated with rhTSH plus ${ }^{131}$ I compared to those treated with ${ }^{131}$ I alone [13], while in the study of Marcia et al., they got a dramatically different result [14]. Therefore, we performed a meta-analysis to assess the effect of rhTSH stimulation before ${ }^{131}$ I therapy in MNG and determine an optimal dose for different follow up time after treatment.

\section{Materials and Methods}

\section{Search strategy for identification of studies}

We identified studies by searching the PubMed, Cochrane, CNKI, VIP, and Wanfang database. The search strategy to identify all potential studies involved is (multinodular goiter or MNG or thyroid nodules or nodular thyroid disease or nontoxic goiter)" and ("re- combinant human TSH" or "recombinant human thyrotropin" or "recombinant human thyroid-stimulating hormone" or "TSH" and "rhTSH") and ("radiotherapy" or "iodine-131" or "radioiodine therapy" or radioiodine). We added a manual search using the reference lists of the relevant articles. No language restriction was imposed.

\section{Eligibility and excluded criteria}

Eligibility criteria: (1) Randomized controlled trials (RCTs); (2) Patients of any age receiving rhTSH stimulated ${ }^{131}$ I therapy for MNG, while MNG had been adequately defined; (3) Trials investigating the effects of rhTSH, which was injected $24 \mathrm{~h}$ before ${ }^{131}$ I therapy that was included as an adjuvant to ${ }^{131}$ I therapy, and only clinical trials with both randomized controlled design and at least 6 months follow up data were analyzed. Patients undergoing ${ }^{131}$ I therapy without rhTSH served as controls. The main outcome measure was the GV reduction. Secondary outcome was hypothyroidism incidence. Trials are excluded if there was no control group or the follow up time was not enough. And, non-RCT trials or/and trials of patients with non-MNG or/and trials without rhTSH as experimental group or/and GV reduction not mentioned were excluded.

\section{Study selection and data collection process}

Two reviewers read the titles and abstracts of the articles independently. Relative data were extracted from studies by one reviewer, then the extracted data were checked by the second reviewer. Differences were resolved by communication between reviewers.

All information we needed from the included studies were the following: (1) type of disease; (2) type of intervention: dose, rhTSH injection time, measurement instrument, follow-up time; (3) type of outcome measure: GV reduction, incidence of hypothyroidism. The eligible studies were graded with the 5-point Jadad quality scale.

\section{Quantitative data analysis}

Revman Manager software version 5.3 (The Cochrane Collaboration, London, UK) was used for data analysis. Intergroup analyses were based on the change from baseline data. For continuous data, weighted mean differences (WMD) for scales that were the same was used, otherwise standardized mean differences (SMD) was used. Results of GV reductions were combined as WMD with $95 \%$ confidence intervals $(\mathrm{Cl})$ with an inverse variance random-effects model. The $\mathrm{I}^{2}$ was calculated, which can be interpreted as the percentage of the variation between studies that attributes to heterogeneity rather than chance. $I^{2}=0 \%$ indicates no heterogeneity, $\mathrm{I}^{2}>50 \%$ indicates high heterogeneity, and $\mathrm{I}^{2}=100 \%$ represents that all variations derive from heterogeneity. Subgroup analysis by dose of rhTSH (high dose: $>0.1 \mathrm{mg}$; low dose: $<0.1 \mathrm{mg}$ ) was applied to assess the efficacy of different therapeutic dose. Sensitivity analyses excluding one study at a time were also performed to evaluate whether any specific study significantly influenced the overall pooled results. The occurrence of hypothyroidism was presented as odds ratio (OR) with $95 \% \mathrm{Cl}$ using a fixed-effects model for no heterogeneity. Statistical significance for hypothesis testing was set at the 0.05 , 2-tailed level. 


\section{Methodological quality and risk of bias}

Jadad score was conducted to estimate the methodological quality across studies. Jadad score consists of three items, and they are randomization (0-, 1-, 2-point), double blinding (0-, 1-, 2-point), and withdrawals and dropouts (0-, 1-point), respectively. Total score is 5-point. A score of 2 or less is considered as a low-quality study and over or equal to 3 is a high-quality study.

\section{Results}

\section{Selected studies and characteristics}

The electronic database searched 381 identified articles, among which 6 articles covering 9 RCTs (since several articles included more than one trials, they were considered as separate trials) with 237 patients satisfied the inclusion criteria [13-18] ( Fig. 1). High dose including $0.1,0.3$, and $0.45 \mathrm{mg}$ rhTSH were injected to patients prior to iodine 131 therapy in 4 trials with 136 patients $[13,14,16,17]$, the remaining 5 trials with 109 patients were administrated with 0.01 and $0.03 \mathrm{mg}$ rhTSH $[13,15,18]$. All seven trials provide us with the incidence of hypothyroidism [13, 14, 16-18]. The basal characteristics and design features of the included studies are listed in $>$ Table $\mathbf{1}$. The level of evidence for each article was graded with a score of 3 to 5 according to the Jadad quality score ( Table 1).

\section{Quantitative assessment of efficacy of rhTSH injected to patients before ${ }^{131}$ I therapy}

\section{Effect on GV reduction}

Overall, rhTSH injected to patients before ${ }^{131}$ I therapy significantly reduced GV compared to placebo group after both 6 months $\left(\mathrm{MD}=10.66 ; 95 \% \mathrm{Cl}=2.66\right.$ to $18.66 ; \mathrm{p}=0.009 ; \mathrm{I}^{2}=66 \%$, - Fig. $2 \mathrm{a}$ ) and 12 months follow up (MD = 17.64; $95 \% \mathrm{Cl}=12.31$ to 22.97; $p<0.00001 ; I^{2}=0 \%$, > Fig. 2b). However, there was no difference between rhTSH and placebo group in reducing GV after 36-months follow up $\left(\mathrm{MD}=3.15 ; 95 \% \mathrm{Cl}=-8.60\right.$ to $14.91 ; p=0.60 ;\left.\right|^{2}=73 \%$,

- Fig. 2c).

\section{Effect on the risk of hypothyroidism}

RhTSH prior to ${ }^{131}$ I therapy was associated with increased risk of hypothyroidism. Five studies reported the occurrence of hypothyroidism, except for one study [15]. A total of 237 patients were enrolled, and 61 patients out of 136 receiving rhTSH stimulation before radioactive ${ }^{131}$ I therapy developed hypothyroidism, while it was 14 out of 101 in ${ }^{131}$ I monotherapy group. The results have statistical significance $(O R=5.10 ; 95 \% \mathrm{Cl}=2.82$ to $9.21 ; \mathrm{p}<0.00001$; $\mathrm{I}^{2}=0 \%$, Fig. $3 \mathbf{a}$ ). We then conducted planned subgroup analyses according to the dose of rhTSH combined with ${ }^{131}$ I therapy and tested for hypothyroidism incidence. High dose group resulted in higher incidence of hypothyroidism $(\mathrm{OR}=6.01 ; 95 \% \mathrm{Cl}=2.58$ to
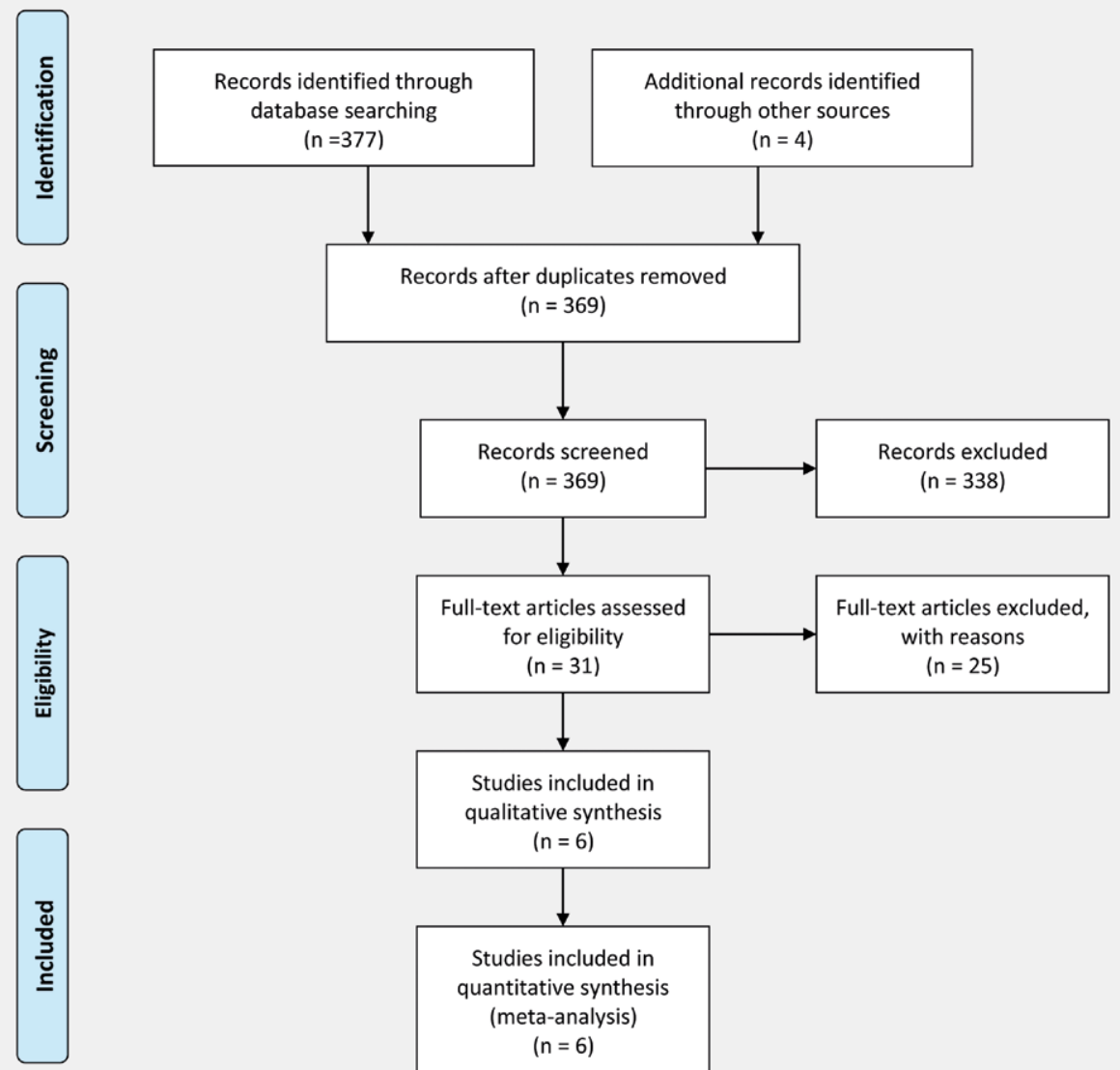

Studies included in qualitative synthesis $(n=6)$

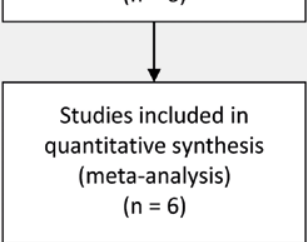

- Fig. 1 Literature search flow diagram. 
- Table 1 Baseline characteristics of clinical trials enrolled in the analyses.

\begin{tabular}{|c|c|c|c|c|c|c|c|c|c|}
\hline \multirow[t]{2}{*}{ Author } & \multirow[t]{2}{*}{ Year } & \multicolumn{3}{|l|}{ Patients } & \multirow{2}{*}{$\begin{array}{l}\text { Mean } \\
\text { follow-up } \\
\text { (months) }\end{array}$} & \multirow{2}{*}{$\begin{array}{l}\text { Measure- } \\
\text { ment } \\
\text { instrument }\end{array}$} & \multicolumn{2}{|c|}{ Intervention } & \multirow{2}{*}{$\begin{array}{l}\text { Jadad } \\
\text { score }\end{array}$} \\
\hline & & $\begin{array}{l}\text { Enrolled a } \\
\text { (n) }\end{array}$ & $\begin{array}{l}\text { Mean age } \\
\text { (years) }\end{array}$ & $\begin{array}{l}\text { Women } \\
(\%)\end{array}$ & & & $\begin{array}{l}\text { Dosageb }^{b} \\
(\mathrm{mg})\end{array}$ & $\begin{array}{l}\text { Injection } \\
\text { timec }^{c}(h)\end{array}$ & \\
\hline Albino (1) & 2010 & $8 / 8$ & 61 & 91 & 6,12 & MRI & 0.1 & 24 & 5 \\
\hline Albino (2) & 2010 & $8 / 6$ & 61 & 91 & 6,12 & MRI & 0.01 & 24 & 5 \\
\hline Silva & 2003 & $17 / 17$ & 63 & 82 & 6,12 & $\mathrm{CT}$ & 0.45 & 24 & 3 \\
\hline Graf (1) & 2011 & $30 / 32$ & 57 & 85 & 6 & $\mathrm{CT}$ & 0.01 & 24 & 4 \\
\hline Graf (2) & 2011 & $33 / 32$ & 57 & 85 & 6 & $\mathrm{CT}$ & 0.03 & 24 & 4 \\
\hline Nielsen & 2006 & $29 / 28$ & 55 & 88 & 6,12 & US & 0.3 & 24 & 4 \\
\hline Bonnema & 2007 & $15 / 14$ & 61 & 76 & 12 & MRI & 0.3 & 24 & 5 \\
\hline Søren Fast (1) & 2014 & $29 / 27$ & 57 & 85 & 36 & $\mathrm{CT}$ & 0.01 & 24 & 4 \\
\hline Søren Fast (2) & 2014 & $30 / 27$ & 57 & 85 & 36 & $\mathrm{CT}$ & 0.03 & 24 & 4 \\
\hline
\end{tabular}

arhTSH group/control group; brhTSH dose combined with ${ }^{131}$ I therapy; c Time of injecting rhTSH before ${ }^{131}$ I therapy. MRI: Magnetic resonance imaging; US: Ultrasonography; CT: Computed tomography; rhTSH: Recombinant human thyrotropin.

a

\begin{tabular}{|c|c|c|c|c|c|c|c|c|}
\hline \multirow[b]{2}{*}{ Study or Subgroup } & \multicolumn{2}{|c|}{ rhTSH } & \multicolumn{3}{|c|}{ placebo } & \multirow[b]{2}{*}{ Total } & \multirow{2}{*}{\multicolumn{2}{|c|}{$\begin{array}{l}\text { Mean Difference } \\
\text { IV. Random, } 95 \% \mathrm{CI}\end{array}$}} \\
\hline & Mean & SD & Total & Mean & SD & & & \\
\hline C.C. Albino, 2010 (1) & 28.5 & 17.6 & 8 & 2.7 & 15.3 & 8 & $14.0 \%$ & $25.80[9.64,41.96]$ \\
\hline C.C. Albino, 2010 (2) & 21.6 & 17.8 & 6 & 2.7 & 15.3 & 8 & $12.6 \%$ & $18.90[1.14,36.66]$ \\
\hline H. Graf, 2011 (1) & 23.3 & 16.5 & 30 & 23.1 & 8.8 & 32 & $26.8 \%$ & $0.20[-6.45,6.85]$ \\
\hline H. Graf, 2011 (2) & 32.9 & 20.7 & 33 & 23.1 & 8.8 & 32 & $25.2 \%$ & $9.80[2.11,17.49]$ \\
\hline Nielsen VE, 2006 & 46 & 15.87 & 28 & 36 & 23.18 & 29 & $21.3 \%$ & $10.00[-0.28,20.28]$ \\
\hline Total $(95 \% \mathrm{Cl})$ & & & 105 & & & 109 & $100.0 \%$ & $10.66[2.66,18.66]$ \\
\hline
\end{tabular}

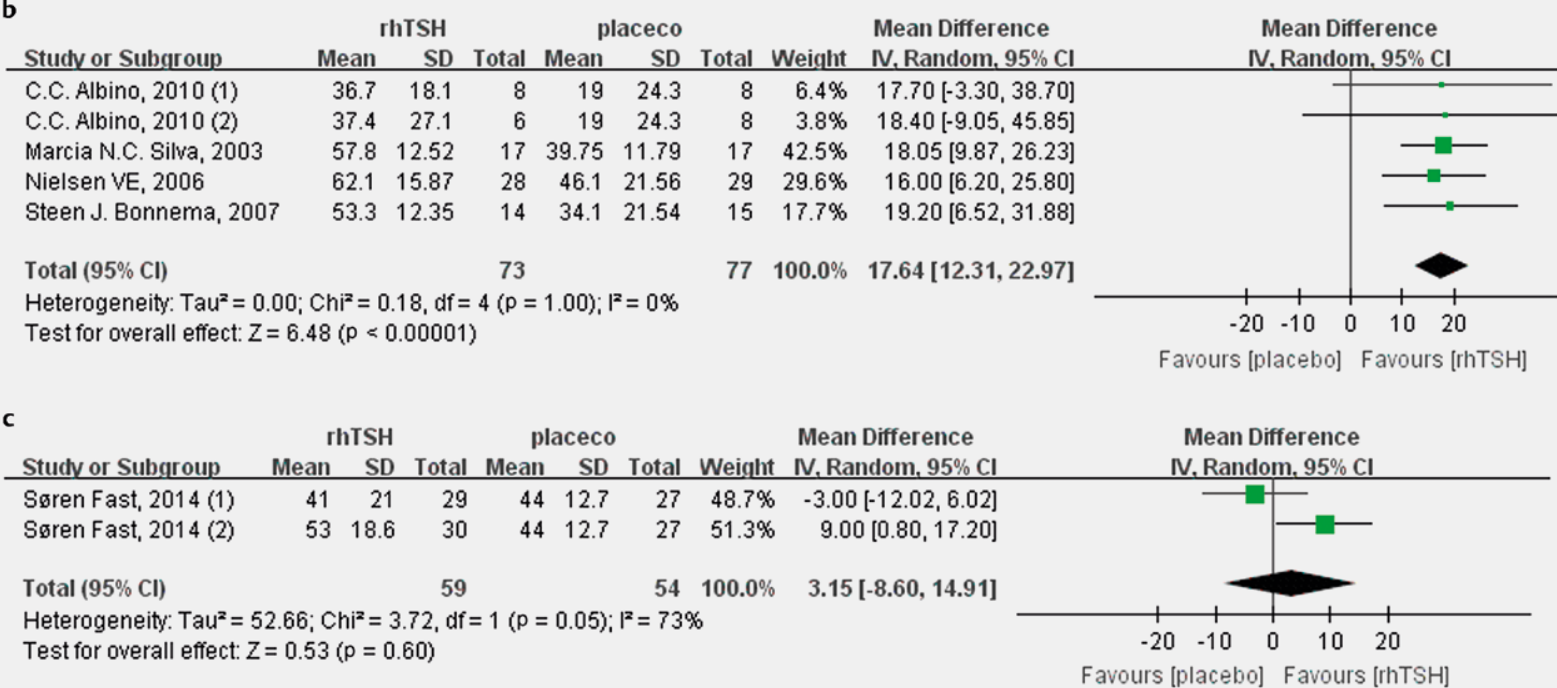

Fig. 2 Forest plot of the GV reduction of MNG patients treated with rhTSH and placebo after 6 (a), 12 (b), and 36 (c) months follow up. MD with $95 \% \mathrm{Cl}$ indicated the relative efficacy. GV: Goiter volume; MNG: Multinodular goiter; MD: Mean difference. 
a

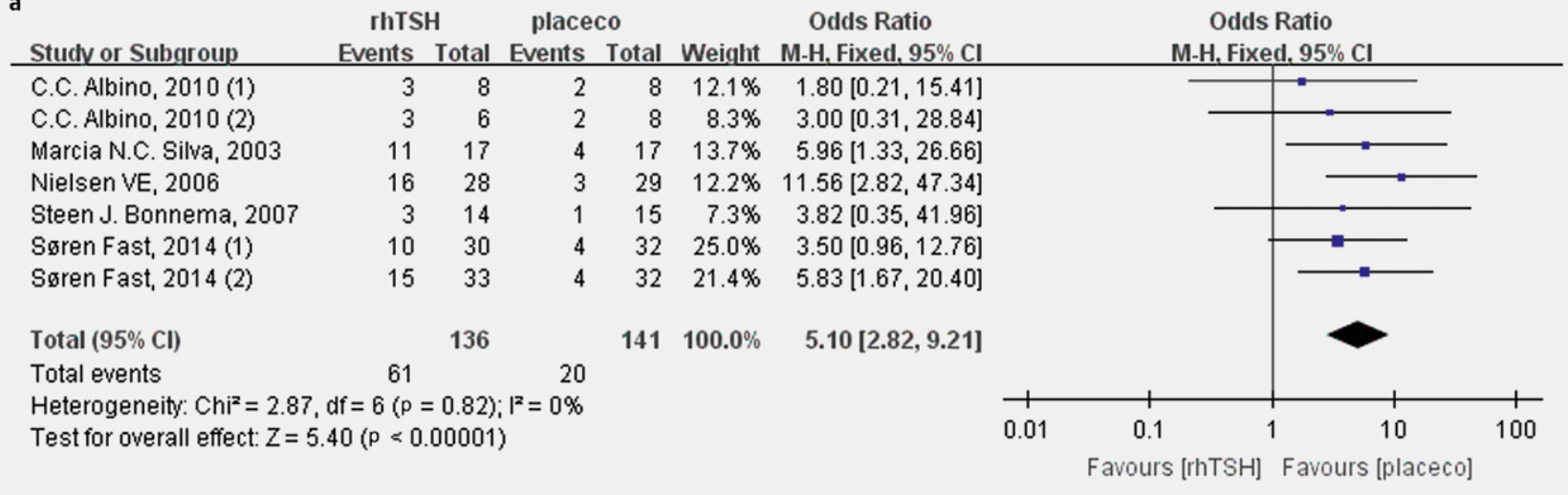

b

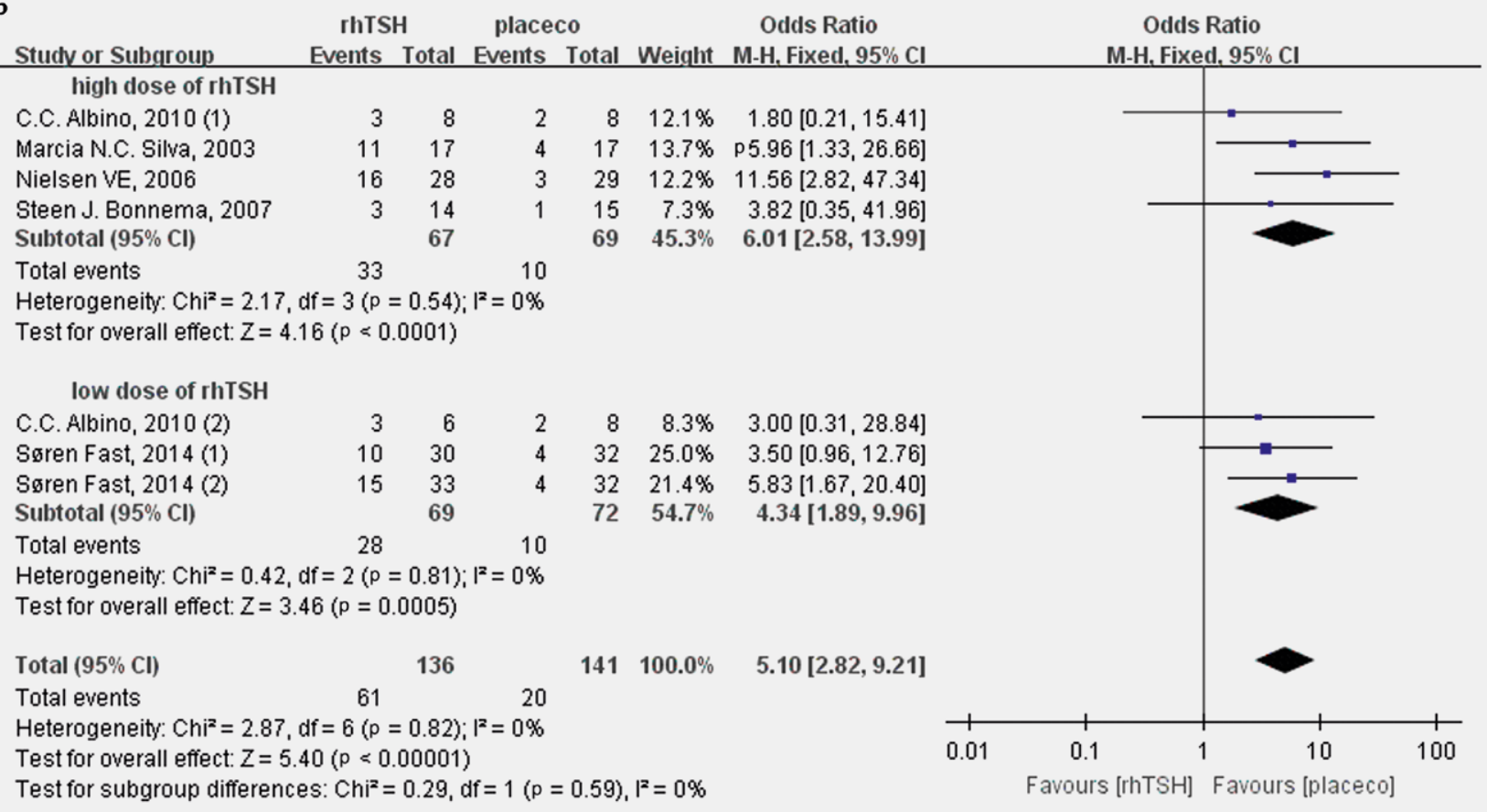

- Fig. 3 Forest plot of the incidence of hypothyroidism. Results were shown by OR with $95 \% \mathrm{Cl}$. OR: Odds ratio.

13.99; $p<0.0001 ; 1^{2}=0 \%$, > Fig. 3b) in contrast to placebo group. Low dose rhTSH also contributed to higher incidence of hypothyroidism $\left(O R=4.34 ; 95 \% C l=1.89\right.$ to $9.96 ; p=0.0005 ; I^{2}=0 \%$, Fig. 3b) compared with placebo, but the incidence of hypothyroidism was lower than high dose group.

Heterogeneity test and subgroup analysis of GV reduction Sources of heterogeneity were explored through subgroup meta-analysis. For 6 months follow up, high dose of rhTSH prior to ${ }^{131}$ I therapy was associated with more obvious GV reduction compared with ${ }^{131}$ I monotherapy by pooling data of three RCTs (MD = 16.62; $95 \% \mathrm{Cl}=1.34$ to $31.90 ; p=0.03 ; r^{2}=62 \%$, > Fig. 4a). Three RCTs compared low-dose rhTSH prior to ${ }^{131}$ I therapy in contrast with ${ }^{131}$ I alone. $G V$ reduction was observed in 69 patients (36 patients with $0.01 \mathrm{mg}$ rhTSH, 33 patients with $0.03 \mathrm{mg}$ rhTSH) who received lowdose rhTSH prior to ${ }^{131}$ I therapy compared with 40 patients treated with ${ }^{131}$ I therapy alone. Low dose of rhTSH prior to ${ }^{131}$ I therapy showed no significant advantage in $\mathrm{GV}$ reduction compared with ${ }^{131}$ I therapy alone $(\mathrm{MD}=7.40 ; 95 \% \mathrm{Cl}=-1.92$ to $16.71 ; \mathrm{p}=0.12$; $\mathrm{I}^{2}=66 \%$, Fig. 4a) with high heterogeneity. Although the substantial heterogeneity existed in high dose of rhTSH group, the source of heterogeneity cannot be determined by sensitivity analyses, which used the leave-one-out method by removing one study at a time and then repeated the analysis, due to only two trials reporting the effect of high dose of rhTSH. And for low dose group, the sensitivity analysis was conducted to determine the source of heterogeneity. The study conducted by Graf et al. [17] was excluded for different sex ratios, and sensitivity analysis result found a more significant decreased effect on GV by low dose of rhTSH (MD = 11.24; $95 \% \mathrm{Cl}=4.18$ to $18.30 ; \mathrm{p}=0.002 ; \mathrm{I}^{2}=0 \%$, - Fig. $\mathbf{4 b}$ ).

In addition, 12 months follow up was performed by 5 RCTs and 142 patients were included. GV reduction was significant in $67 \mathrm{pa}$ tients (8 patients with $0.1 \mathrm{mg}$ rhTSH, 42 patients with $0.3 \mathrm{mg}$ rhTSH and 17 patients with $0.45 \mathrm{mg}$ rhTSH) who received high-dose rhTSH 
a

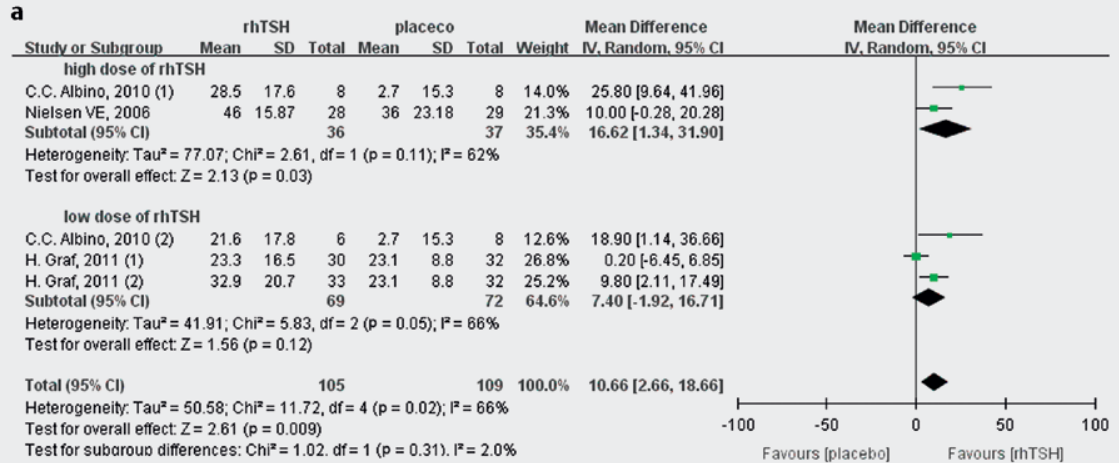

b

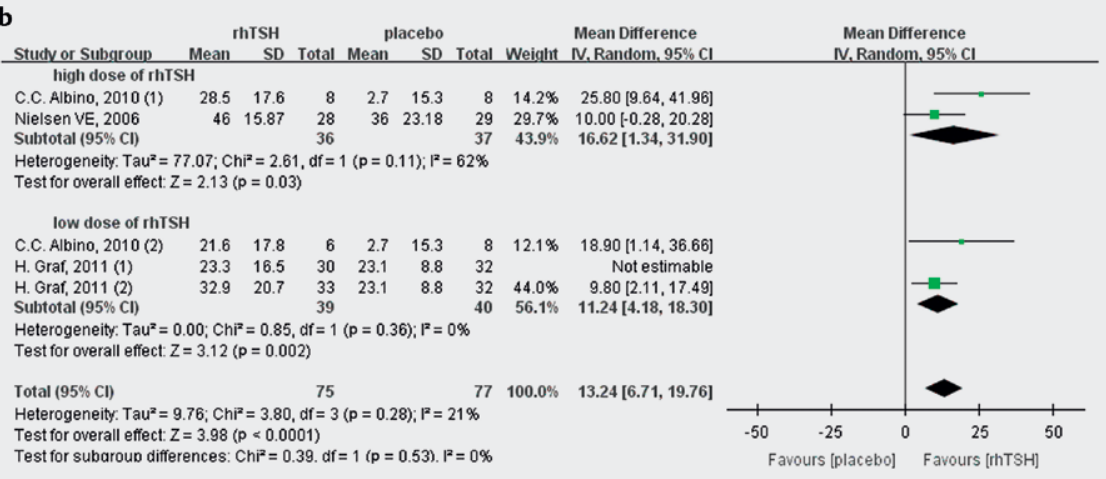

C

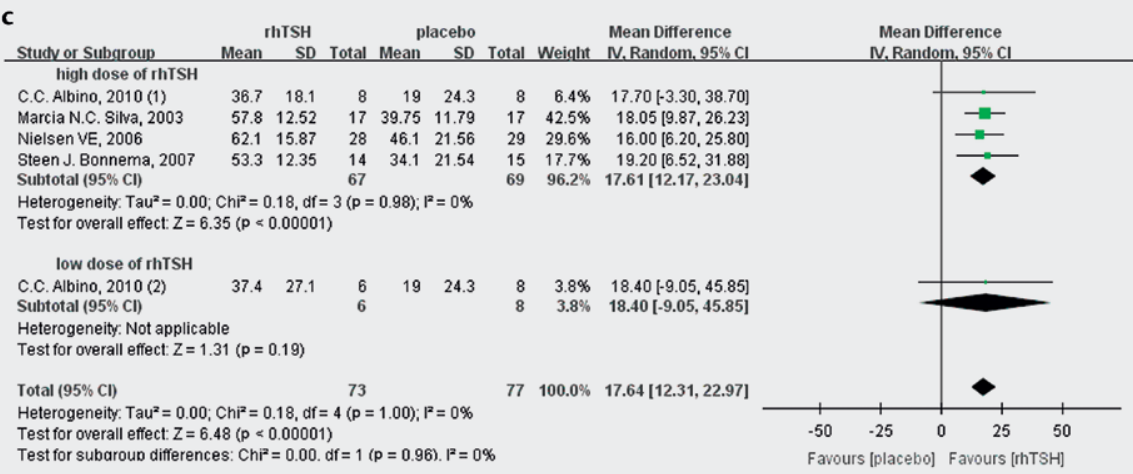

-Fig. 4 a Forest plot of subgroup analysis for the reduction of GV after 6 months' follow up. b Forest plot of sensitivity analysis for the influence of low dose of rhTSH treatment on GV reduction after 6 months' follow up. c Forest plot of subgroup analysis for the reduction of GV after 12 months' follow up. Results were shown by MD with $95 \% \mathrm{Cl}$. GV: Goiter volume; MD: Mean difference.

compared with 69 patients treated with ${ }^{131}$ I therapy alone with no heterogeneity $(\mathrm{MD}=17.61 ; 95 \% \mathrm{Cl}=12.17$ to $23.04 ; \mathrm{p}<0.00001$; $\mathrm{I}^{2}=0 \%$, $\mathbf{\text { Fig. }} \mathbf{4 \mathbf { c }}$ ). One study [13] reported the effect of low-dose rhTSH after 12-months follow up and showed no significant difference in the reduction of GV between low dose of rhTSH and placebo group $(\mathrm{MD}=18.40 ; 95 \% \mathrm{Cl}=-9.05$ to $45.85, \mathrm{p}=0.19$, $\mathbf{\text { Fig. }} \mathbf{4 c}$ ).

\section{Publication bias}

The funnel plots of GV reduction based on 6, 12, and 36 months' follow up are shown in $>$ Fig. $\mathbf{5 a}, \mathbf{b}, \mathbf{c}$, respectively. The funnel plot shapes were symmetrical, indicating no obvious reporting bias.

\section{Discussion}

In the present meta-analysis, six articles [13-18] covering 9 RCTs with 237 patients were included. The results suggested that high dose of rhTSH injected to patients before ${ }^{131}$ I therapy significantly reduced GV compared to the patients with ${ }^{131}$ I monotherapy after both 6 and 12 months follow up, but the risk of hypothyroidism was higher. Together, pooled subgroup analyses showed that high-dose rhTSH stimulation before ${ }^{131}$ I therapy had a significant advantage in GV reduction after 12 months follow up than that of 6 months follow up. However, only two RCTs reported the decreased effect on the GV of treatment with high dose of rhTSH after 6 months follow up, thus the results must be interpreted with caution. Furthermore, low-dose rhTSH stimulation after follow up for 6 months gained a better effect on $G V$ reduction than placebo. Whereas low- 

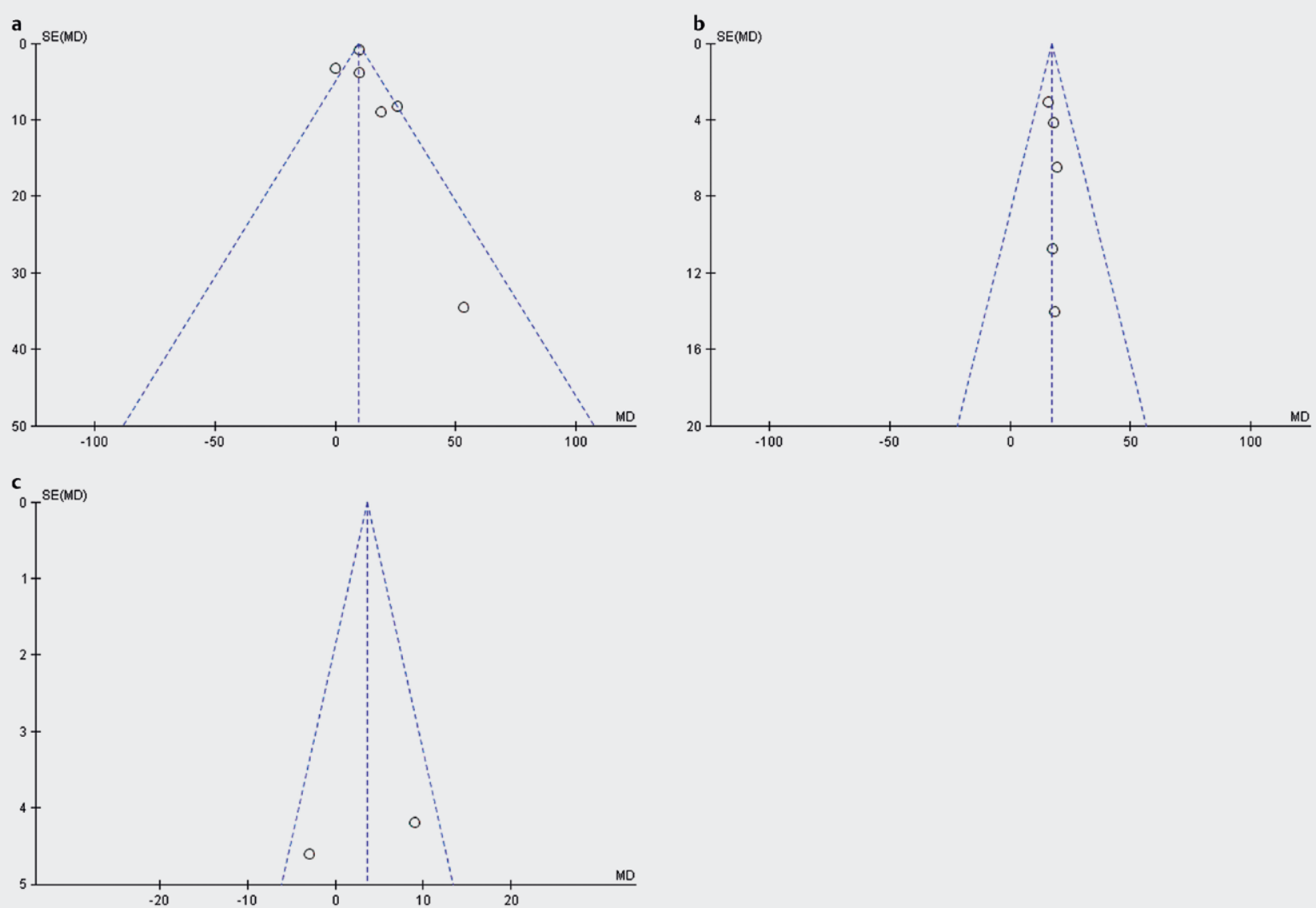

Fig. 5 Funnel plots of GV reduction after 6 (a), 12 (b), and 36 (c) months' follow up revealed no significant publication bias. GV: Goiter volume; MD: Mean difference; SE (MD): Standard error of mean difference.

dose rhTSH treatment after 12 months follow up achieved no significant advantage in GV reduction for only one $\mathrm{RCT}$ reporting the effect of low-dose rhTSH treatment after 12-months follow up. These findings may be helpful for future study in determining the optimal dose of rhTSH stimulation before ${ }^{131}$ I therapy which matches different follow-up time.

In patients with MNG, an unrestricted air flow may be jeopardized due to deformation of the trachea [19]. Currently, there is still no consensus in MNG treatment. Due to low efficacy and the potential risk of surgical complications, LT4 therapy and surgery are not commonly used at all [4-6]. During the last two decades, ${ }^{131}$ I therapy has, in some countries, become the cornerstone in the treatment of patients with MNG [20]. It is reported that ${ }^{131}$ I therapy can result in a mean thyroid volume reduction ranging from 40-60\% within 1-2 years after treatment [8]. However, many physicians are still reluctant to choose this therapeutic method $[20,21]$. Because MNG is often large, and frequently corresponding RAIU is low resulting in a relatively low ${ }^{131}$ I activity, which is not good for satisfactory goiter shrinkage [22].

RhTSH has become available for diagnostic use in patients with differentiated thyroid cancer $[23,24]$. With the recent advent of rhTSH which has been shown to approximately double the $24 \mathrm{~h}$ thyroid RAIU of MNG $[9,10]$, the possibility of increasing the absorbed radioactive dose in the thyroid gland appears promising in dealing with the limited effect of ${ }^{131}$ I therapy. Albino et al. showed that GV reductions were not statistically different in patients treated with rhTSH plus ${ }^{131}$ I compared to those treated with ${ }^{131}$ I alone [13], while in the study of Marcia et al., they got a dramatically different result [14]. But whether rhTSH combined with ${ }^{131}$ I therapy showed a GV reduction advantage and what is the suitable dose for different follow-up time of therapy are disputed.

By conducting a systematic review, we obtained an estimate that high dose of rhTSH injected to patients before ${ }^{131}$ I therapy significantly reduced GV compared to the patients with ${ }^{131} \mathrm{I}$ monotherapy. The mechanism of rhTSH enhancing GV reduction combined with ${ }^{131}$ I therapy in MNG remains unclear. The reason might be associated with enhanced uptake of the radioactive iodine and prolonged permanency of the radioisotope within the gland thyroid. Experimental studies also showed that the plausible explanation of the preconditioning effect of rhTSH was a more homogeneous distribution of ${ }^{131}$ I within the goiter [25]. Moreover, a rhTSH-induced reactivation of dormant thyroid tissue, increased thyroid sensitivity to ionizing radiation, and a higher rate of apoptosis of the thyrocytes could contribute to the enhancement of GV reduction $[16,17,26]$. 
The development of hypothyroidism is a late adverse effect of ${ }^{131}$ I therapy [27]. In this study, the incidence of hypothyroidism was significantly higher in patients receiving high dose of rhTSH stimulated ${ }^{131}$ I therapy. This most likely resulted from a higher retained and more homogeneous distribution of ${ }^{131} \mathrm{I}$ in thyroid [25]. LT4 replacement therapy is usually straightforward after ${ }^{131}$ I therapy [28], thus hypothyroidism should not be a major argument against rhTSH-augmented GV reduction effect.

What is important in our analysis is that when the moderate heterogeneity was taken into account. Due to nonnegligible heterogeneity after 6 months follow up, pooled subgroup analyses about different degree of dose were conducted and showed that highdose rhTSH stimulation before ${ }^{131}$ I therapy had a significant advantage in GV reduction with still existing heterogeneity and the similar results were observed as low dose group. For high dose group, due to only two RCTs which were included in our analysis evaluating the decreased effect of high dose of rhTSH on GV reduction, it was not suitable to conduct the sensitivity analysis to determine the source of heterogeneity and the result needed to be explained with caution. For low dose group, when we performed sensitivity analysis, heterogeneity disappeared eventually. Therefore, for short-term observation after treatment, high dose of rhTSH could obtain a more ideal result but more studies were needed to assess the influence of high dose of rhTSH.

Several limitations need to be considered. First, there was a discrepancy in the methodological quality across the included trials. Additionally, since no authors mentioned the lower limit of normal serum-free T4 in the included articles, the definition of hypothyroidism as the main adverse effect of rhTSH administration might be inconsistent in various studies, which increased the clinical heterogeneity. Other factors, such as sample sizes, and the methodology of GV measurement might also influence the results of our analyses. Furthermore, there was no available data concerning the costs of rhTSH injection in the included trials, and differences in cost were not considered.

\section{Conclusions}

To summarize, high dose of rhTSH injection before ${ }^{131}$ I therapy significantly reduced $\mathrm{GV}$ compared to that of ${ }^{131}$ I monotherapy after both 6 and 12 months follow up. Whereas, a higher incidence of hypothyroidism was observed in MNG patients receiving rhTSH administration than those who received placebo treatment, especially in those received high-dose rhTSH treatment. Finally, our findings might help the clinicians to determine the optimal dose of rhTSH stimulation before ${ }^{131}$ I therapy, especially for some MNG patients who had surgical contraindications or reluctance to perform surgery. Furthermore, larger high-quality RCTs are required to further validate the above conclusions, especially for the observation after 36 months follow up in future.

\section{Funding Information}

This work was funded by National Natural Science Foundation of China Grants (No. 81770822, 81800732), Shandong Provincial Natural Science Foundation of China Grants (No. ZR2017LH025, ZR2016HQ26, Y2008C73, ZR2010HM044), The development of science and technology of JiNan City (No. 201602172), and Shandong Provincial Medicine and Health Science and Technology Development Program (No.2017WS461).

\section{Conflict of Interest}

The authors declare that they have no conflict of interest.

\section{References}

[1] Knobel M. Etiopathology, clinical features, and treatment of diffuse and multinodular nontoxic goiters. J Endocrinol Invest 2016; 39: 357-373

[2] Bandeira-Echtler E, Bergerhoff K, Richter B. Levothyroxine or minimally invasive therapies for benign thyroid nodules. Cochrane Database Syst Rev 2014; 18: CD004098

[3] Dogan L, Karaman N, Yilmaz KB et al. Total thyroidectomy for the surgical treatment of multinodular goiter. Surg Today 2011; 41: 323-327

[4] Gharib H, Papini E, Paschke R et al. AACE/AME/ETA Task Force on Thyroid Nodules of the American Association of Clinical Endocrinologists, Associazione Medici Endocrinologi, and European Thyroid Association medical guidelines for clinical practice for the diagnosis and management of thyroid nodules: Executive summary of recommendations. Endocr Pract 2010; 16 (Suppl 1): 468-475

[5] American Thyroid Association (ATA) Guidelines Taskforce on Thyroid Nodules and Differentiated Thyroid Cancer Cooper DS, Doherty GM et al. Revised American Thyroid Association management guidelines for patients with thyroid nodules and differentiated thyroid cancer. Thyroid 2009; 19: 1167-1214

[6] Sorensen JR. The impact of surgery on quality of life, esophageal motility, and tracheal anatomy and airflow in patients with benign nodular goiter. Dan Med J 2018; 65: B5472

[7] Braverman L, Kloos RT, Law B Jr et al. Evaluation of various doses of recombinant human thyrotropin in patients with multinodular goiters. Endocr Pract 2008; 14: 832-839

[8] Medeiros-Neto G. Multinodular Goiter. In: Feingold KR, Eds. Endotext [Internet].South Dartmouth: MDText; .com, Inc.;2000

[9] Bonnema S], Fast S, Hegedüs L. Non-surgical approach to the benign nodular goiter: New opportunities by recombinant human TSH-stimulated 1311-therapy. Endocrine 2011; 40: 344-353

[10] Ceccarelli C, Antonangeli L, Brozzi F et al. Radioiodine 131I treatment for large nodular goiter: recombinant human thyrotropin allows the reduction of radioiodine 1311 activity to be administered in patients with low uptake. Thyroid 2011; 21: 759-764

[11] Mojsak MN, Abdelrazek S, Szumowski P et al. Single, very low dose $(0.03 \mathrm{mg})$ of recombinant human thyrotropin (rhTSH) effectively increases radioiodine uptake in the I-131 treatment of large nontoxic multinodular goiter. Nucl Med Rev 2016; 19: 3-11

[12] Azorín Belda MJ, Martínez Caballero A, Figueroa Ardila GC et al. Recombinant human thyrotropin stimulation prior to 1311 therapy in toxic multinodular goiter with low radioactive iodine uptake. Rev Esp Med Nucl Ima 2017; 36: 7-12

[13] Albino CC, Graf H, Paz-Filho G et al. Radioiodine plus recombinant human thyrotropin do not cause acute airway compression and are effective in reducing multinodular goiter. Braz J Med Biol Res 2010; 43: 303-309

[14] Silva MN, Rubió IG, Romão R et al. Administration of a single dose of recombinant human thyrotrophin enhances the efficacy of radioiodine treatment of large compressive multinodular goiters. Clin Endocrinol 2004; 60: 300-308 
[15] Graf H, Fast S, Pacini F et al. Modified-Release Recombinant Human TSH (MRrhTSH) augments the effect of 131 therapy in benign multinodular goiter: results from a multicenter international, randomized, placebo-controlled study. J Clin Endocrinol Metab 2011; 96: 1368-1376

[16] Nielsen VE, Bonnema S], Boel-Jørgensen $\mathrm{H}$ et al. Stimulation with $0.3-\mathrm{mg}$ recombinant human thyrotropin prior to iodine 131 therapy to improve the size reduction of benign nontoxic nodular goiter: $\mathrm{A}$ prospective randomized double-blind trial. Arch Intern Med 2006; 66: 1476-1482

[17] Bonnema SJ, Nielsen VE, Boel-Jørgensen $\mathrm{H}$ et al. Improvement of goiter volume reduction after $0.3 \mathrm{mg}$ recombinant human thyrotropin-stimulated radioiodine therapy in patients with a very large goiter: A double-blinded, randomized trial. J Clin Endocrinol Metab 2007; 92: 3424-3428

[18] Fast S, Hegedüs L, Pacini F et al. Long-term efficacy of modified-release recombinant human thyrotropin augmented radioiodine therapy for benign multinodular goiter: Results from a multicenter, international, randomized, placebo-controlled, dose-selection study. Thyroid 2014; 24: 727-735

[19] Bonnema SJ, Nielsen VE, Boel-Jørgensen $\mathrm{H}$ et al. Recombinant human thyrotropin-stimulated radioiodine therapy of large nodular goiters facilitates tracheal decompression and improves inspiration. J Clin Endocr Metab 2008; 93: 3981-3984

[20] Jasim S, Gharib H. Multinodular Goiter. In: Gharib H, Ed. Thyroid Nodules. Contemporary Endocrinology. Cham: Humana Press; 2018: $135-152$
[21] Charalambous A. Seeking optimal management for radioactive iodine therapy-induced adverse effects. Asia Pac J Oncol Nurs 2017; 4: 319-322

[22] Fast S, Nielsen VE, Bonnema SJ et al. Time to reconsider nonsurgical therapy of benign non-toxic multinodular goitre: Focus on recombinant human TSH augmented radioiodine therapy. Eur J Endocrinol 2009; 160: 517-528

[23] Nguyen QT, Lee E], Huang MG et al. Diagnosis and treatment of patients with thyroid cancer. Am Health Drug Benefits 2015; 8: 30-40

[24] Haugen BR, Alexander EK, Bible KC et al. 2015 American Thyroid Association management guidelines for adult patients with thyroid nodules and differentiated thyroid cancer: The American Thyroid Association guidelines task force on thyroid nodules and differentiated thyroid cancer. Thyroid 2016: 1-133

[25] Bonnema S], Hegedus L. Nontoxic Goiter. In: Vitti P, Hegedus L, Eds. Thyroid Diseases. Endocrinology. Cham: Springer; 2017: 1-38

[26] Giusti M, Caorsi V, Mortara L et al. Long-term outcome after radioiodine therapy with adjuvant rhTSH treatment: comparison between patients with non-toxic and pre-toxic large multinodular goitre. Endocrine 2014; 45: 221-229

[27] Bonnema S], Hegedüs L. Radioiodine Therapy in Benign Thyroid Diseases: Effects, side effects, and factors affecting therapeutic outcome. Endocr Rev 2012; 33: 920-980

[28] Sheehan MT, Doi SA. Transient hypothyroidism after radioiodine for Graves' disease: Challenges in interpreting thyroid function tests. Clin Med Res 2016; 14: 40-45 